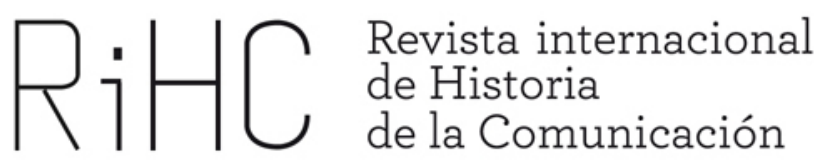

\title{
LA DIFÍCIL AUTONOMÍA DE JOSÉ LUIS CEBRIÁN COMO DIRECTOR DEL DIARIO ABC, 1975-1977
}

DOI: http://dx.doi.org/10.12795/RiHC.2017.i08.03

Carlos Barrera

Universidad de Navarra (España)

cbarrera@unav.es

Raquel Ramos-Rugel

Universidad de Piura (Perú)

raquel.ramos@udep.pe

Recibido: 2017

Aceptado: 25-5-2017

Resumen: La breve dirección de José Luis Cebrián en ABC (febrero 1975-octubre 1977) coincidió con el final del tardofranquismo, los comienzos de la transición y una incipiente crisis en el diario. Tras su controvertida designación, fue relegado a funciones meramente periodísticas mientras el control ideológico-político del diario continuó en las manos de Torcuato Luca de Tena. El supuesto fracaso de Cebrián, hombre más bien apolítico, se debió en buena medida a razones empresariales y políticas externas a él dado que $A B C$ adoptó una orientación confusa y extremadamente conservadora, como se refleja en unas normas entregadas al director que se publican por vez primera. 
Palabras clave: $A B C$, José Luis Cebrián, transición, prensa, España

\begin{abstract}
The short period of José Luis Cebrián as editor of ABC (February 1975-October 1977) coincided with the end of Franco's dictatorship, the beginnings of the transition to democracy, and an incipient crisis in the newspaper. After his controversial appointment, he was entrusted to run the newsroom while the ideological and political control continued in the hands of the former editor Torcuato Luca de Tena. The alleged failure of a rather apolitical man like Cebrián was greatly due to business and political reasons external to him because $A B C$ adopted extremely conservative positions, as an until now unpublished document delivered to the editor proves.
\end{abstract}

Keywords: $A B C$ newspaper, José Luis Cebrián, transition to democracy, printed press, Spain

\title{
Introducción
}

La problemática andadura del diario monárquico conservador $A B C$ durante la transición democrática había empezado a manifestarse ya -con otros matices- en los últimos años del tardofranquismo. No fue un camino fácil por diversas razones que varios autores han apuntado (Alférez, 1986; Barrera, 1995; Olmos, 2002). Algunas venían del contexto general de la prensa de la época mientras otras eran más específicas de $A B C$.

Dos circunstancias añadidas en los estertores del franquismo, sucedidas casi a la par, fueron el fallecimiento del patrón Juan Ignacio Luca de Tena (hijo del fundador Torcuato) en enero de 1975 y el controvertido nombramiento de José Luis Cebrián Boné como nuevo director al mes siguiente. El breve mandato de este último se alargaría hasta octubre de 1977, cuando fue cesado. Guillermo Luca de Tena, uno de los dos hijos varones de Juan Ignacio, tomó las riendas del periódico a la par que las de la empresa editora Prensa Española, de la que ya era presidente. Para entonces, la situación de $A B C$ y de su sociedad editora, que ya había empezado a empeorar a comienzos de la década, se había tornado más borrascosa tanto en lo económico como en lo periodístico pues la difusión del diario seguía descendiendo.

La figura de Cebrián como director del diario requiere análisis más profundos debido a varios factores: su relativamente escasa duración de apenas dos años y medio; el hecho de que fuera alguien que no procedía de la casa, por lo que ha pasado a la historia más como una especie de paréntesis que como un protagonista relevante; y la habitual discreción del propio protagonista, que no ha querido habitualmente dar demasiados detalles de forma pública sobre las intrigas internas en las que se vio envuelto. 
En este sentido se puede decir que el paso de José Luis Cebrián por $A B C$, sin ser por supuesto desconocido, ha quedado en un segundo plano o en una especie de olvido relativo dentro de su carrera, sobre todo si se compara esta etapa con la mayor atención y estudio que han merecido otras anteriores y más brillantes de su carrera periodística: la dirección de El Alcázar (1963-1967) y Nuevo Diario (1967-1968), ambas creaciones de Prensa y Ediciones, S.A. (PESA), e incluso sus primeras experiencias como joven director del Diario Regional de Valladolid (1957-1958) y de la revista semanal gráfica La Actualidad Española (1961-1963 y 1969-1975). Su itinerario profesional había sido hasta entonces casi meteórico y desarrollado en plena juventud dado que había nacido un 26 de marzo de 1933 en Barcelona.

Tanto en los primeros tiempos de apertura periodística en los años sesenta con la Ley Fraga como en los más libres y densos de la primera transición que le tocó vivir ya desde la atalaya de $A B C$, Cebrián se mostró como un director básicamente apolítico. En algunas entrevistas concedidas en los años sesenta y primeros setenta se había autodefinido como "absolutamente europeísta" y "cerebralmente monárquico" (Rodríguez Virgili, 2005: 195), pero sin tendencia específica determinada, lo que lleva a Pérez López (1994: 212) a calificar su actividad profesional como de una "ingenua independencia en lo que a política se refiere"; ingenua porque tuvo sus encontronazos con la censura como director de Diario Regional. Poseía un notable sentido de la actualidad periodística y, por mor de las circunstancias de aquellos tiempos, también política; de ahí que los periódicos que dirigiera se vieran envueltos en las dinámicas y controversias propias de esos años clave en la historia contemporánea de España. Si informó y cubrió temas políticos fue porque "vendían", porque existía una demanda creciente de información y de opinión en torno a ellos que había que satisfacer. $Y$ uno de los principios de actuación que guiaron habitualmente su conducta como director de periódicos fue la atención a los lectores (Rodríguez-Virgili, 1995: 192). Se distinguió, en ese sentido, como ha sido reconocido generalmente, por ser un periodista con gran olfato de la actualidad y con instinto para satisfacer, adivinar o adelantarse a las demandas de la audiencia (Alférez, 1986: 128-131).

Su fracasada gestión al frente de $A B C$, si tenemos en cuenta su desenlace y los pobres resultados económicos y periodísticos obtenidos, tiene varias explicaciones que ya han sido ofrecidas por diversos autores. No obstante, no se ha hecho hincapié de forma más concluyente y probada en la falta de autonomía de que disfrutó y que limitó su capacidad de acción. Este es el principal objetivo de este trabajo.

Otros factores relevantes a considerar están relacionados con el contexto complejo y cambiante de la prensa de entonces. El esperado "boom" de la prensa escrita tras la muerte de Franco, aunque real, fue limitado. Si las circunstancias de una mayor libertad de prensa -aún con cautelas y restricciones- propiciaron la salida al mercado de nuevos periódicos y revistas de un amplio espectro ideológico, las condiciones del 
contexto económico general no ayudaron a su consolidación. En efecto, el índice de defunciones fue elevado debido a la crisis económica que afectó tanto a la inversión publicitaria como al consumo (Iglesias, 1980a). En el caso específico de los medios escritos más veteranos, la necesidad de una reconversión tecnológica para competir con los nuevos diarios surgidos se vio entorpecida por la falta de recursos financieros para afrontarla. Además, sus mastodónticas estructuras empresariales, y en especial sus sobredimensionadas plantillas, no ayudaban a tal empeño. Fueron los casos de diarios como $L a$ Vanguardia, $Y a$ y $A B C$, por señalar los más significativos a nivel nacional (Alférez, 1986; Nogué y Barrera, 2006).

Desde el punto de vista jurídico-legal, aun siguiendo vigente la Ley de Prensa e Imprenta de 1966 (solo afectada por una derogación parcial de sus aspectos más punitivos por el decreto del 1 de abril de 1977 sobre libertad de expresión), los periódicos y revistas se lanzaron a ensanchar los límites de esa supuesta mayor libertad. Se aprovecharon hábilmente de su posición privilegiada respecto a otros medios, ganada a pulso en el tardofranquismo gracias al esfuerzo de unos pocos (Aguilar, 1982; Santos, 1995). De esta etapa vinieron ya entrenados en informar y opinar aunque fuera a contracorriente y bajo la espada de Damocles de las sanciones y suspensiones de la ambigua y arbitraria Ley Fraga (Crespo de Lara, 1988). A la altura de noviembre de 1975, la radio y la televisión se hallaban más férreamente controladas por el régimen (Bustamante, 2013).

En el caso concreto de $A B C$, a este panorama general de cambios y crisis había que sumarle varios episodios que habían originado enfrentamientos internos $y$ un retroceso en su hasta entonces indiscutible liderazgo en la prensa nacional. Los fallidos proyectos empresariales, a comienzos de los años setenta, de los talleres gráficos Barajas y del $A B C$ de las Américas, crearon larvadas divisiones y críticas internas, que se hicieron más abiertas tras el fallecimiento del segundo Marqués de Luca de Tena, Juan Ignacio, en enero de 1975. Sus dos hijos varones, Torcuato y Guillermo, se disputaron el mando dentro de la familia, cuyos miembros eran accionistas al completo de la sociedad editora Prensa Española (Alférez, 1986: 23-43; De Lorenzo, 1983: 229-290).

En ese ínterin los adversarios de Torcuato, director de $A B C$ desde 1962, maniobraron para conseguir su reemplazo (Olmos, 2002: 505-521). Descartadas por distintos motivos otras opciones de dentro de la casa como Pedro de Lorenzo, director adjunto, y Luis María Anson, uno de los subdirectores, se optó por contratar a José Luis Cebrián. Entonces director de La Actualidad Española, ya había sido contactado por los Luca de Tena para sacar un Blanco y Negro vespertino en 1969, pero Fraga lo prohibió tajantemente a pesar de que Cebrián incluso había hecho ya un bosquejo de lo que sería la nueva publicación (De Lorenzo, 1983: 235-236; Pérez Mateos, 2002: 502-503). Se confiaba en la demostrada capacidad de Cebrián de reactivar periódicos, como ya 
había hecho con El Alcázar de PESA en los años sesenta. Devolver a $A B C$ a las sendas del liderazgo periodístico estuvo por encima de otras consideraciones a la hora de elegir capitán de la nave, incluso el hecho de que el nombramiento no sentó bien en los altos cuadros de la redacción.

La transición de $A B C$, por tanto, empezó no con la muerte de Franco sino casi un año antes. La decisión de nombrar director a Cebrián coincidiría enseguida con la transición política propiamente dicha en España, añadiendo así un elemento más de incertidumbre a la andadura del buque insignia de Prensa Española. La entrada en escena de nuevos diarios de difusión nacional en 1976 como El País, sobre todo, y Diario 16, suponían otros tantos desafíos para enderezar el rumbo de $A B C$ en cuanto a ventas y rentabilidad pero también en cuanto a liderazgo como periódico de referencia.

\section{Estado de la cuestión, metodología e hipótesis}

Libros de diversa naturaleza han relatado, de forma monográfica o en algunos de sus capítulos, la historia de $A B C$ en estos años del tardofranquismo y la transición. De índole estrictamente académica y centrado básicamente en el aspecto empresarial es el libro de Francisco Iglesias (1980b), que abarca toda la historia de Prensa Española desde sus orígenes hasta 1978. Un relato en clave autobiográfica fue el escrito por Pedro de Lorenzo en 1983, protagonista directo de muchos episodios internos de aquel $A B C$. El excesivo tono literario y reivindicativo de su persona con que está escrito merma en ocasiones su credibilidad aunque resulta una interesante fuente de parte. Antonio Alférez escribió en 1986 varias páginas sobre el diario monárquico en su libro, de claro carácter divulgativo, dedicado a la prensa en España desde la Ley Fraga, manejando fuentes personales de interés. Más adelante, otro libro de carácter entre académico y divulgativo trataba de forma somera la historia de $A B C$ en aquellos años (Barrera, 1995), dentro del contexto general de los medios de comunicación, también los no escritos, de su época.

A comienzos del siglo XXI, coincidiendo con el centenario de $A B C$, salieron al mercado sendos libros, entre la historia y la evocación, escritos por Olmos y por Pérez Mateos, ambos en el 2002. Son, sin duda, los más voluminosos y en ocasiones aportan fuentes nuevas, básicamente orales, para intentar arrojar luz sobre los acontecimientos, si bien su tono general está también más volcado hacia la divulgación que hacia la investigación histórica. Años más tarde se publicó una especie de biografía autorizada de Luis María Anson (Forcada y Lardiés, 2010), en la que se tratan aspectos 
relacionados con la vida de $A B C$ desde la perspectiva del personaje, incluyendo brevemente los años de la transición durante los que él estuvo al frente de la agencia Efe. Muchos años antes, Pedro J. Ramírez, con la ayuda de Marta Robles, ya había escrito en 1991 -en una especie de autobiografía- sus experiencias como redactor en la sección política de $A B C$ entre 1975 y 1980, siempre desde un prisma bastante personalista como resulta habitual en bastantes de sus obras.

Otros trabajos de una índole más científica, cuya enumeración exhaustiva sería excesivamente prolija, han tratado a $A B C$ no tanto como objeto exclusivo de investigación sino como fuente para la descripción de la opinión pública en los años de la transición, dado su carácter de periódico de referencia. Así, un número amplio de proyectos de investigación y tesis doctorales han acudido a él como fuente. Baste aquí con mencionar el ejemplo del libro de Zugasti (2007) sobre el tratamiento de la monarquía en la prensa de la transición.

En general, toda esta literatura sobre el tema ha repetido, en bastantes ocasiones, las mismas tesis de fondo sobre los problemas ya mencionados de $A B C$, o ha descrito con ejemplos algunas posiciones reticentes a la reforma política por parte del diario en sus editoriales y en las firmas de sus colaboradores principales como Torcuato Luca de Tena, José María Ruiz-Gallardón y Gonzalo Fernández de la Mora. Se advertía en ellas una deriva neofranquista que alejaba a $A B C$ de las tendencias de opinión generalizadas en la opinión pública española y que se verían además refrendadas por los resultados electorales del 15 de junio de 1977 . Se ha presentado a $A B C$, con fuentes de hemeroteca, como un diario que a menudo fue a contracorriente de la reforma. Claros ejemplos fueron sus recelos hacia hechos como la legalización del PCE, el restablecimiento de la Generalitat de Cataluña y la amnistía general, ocurridos entre abril y octubre de 1977.

Dentro de estos trabajos sobre $A B C$, es habitual presentar al nuevo director José Luis Cebrián no tanto como culpable sino como una especie de prisionero atrapado entre las borrascas internas y externas en la que se vio envuelto el periódico. Se ha repetido el comentario que recogió primero Pedro de Lorenzo en su libro, puesto en labios de Ruiz Gallardón, quien "con desparpajo alegre" se dirigió así a Cebrián: “Porque a ti te hemos traído para que vendas periódicos... Para dirigir, ya estamos nosotros" (De Lorenzo, 1983: 236). Ciertamente existían órganos internos como la Junta de Fundadores, prevista por la Ley de Prensa, y el Consejo de Dirección, encargados de velar por el rumbo ideológico-político del periódico. Legalmente, sin embargo, el director era el responsable último del diario, por lo que el peso de un posible fracaso podía recaer sobre él. 
En el presente artículo se aportan elementos que explican y explicitan mejor el cariz y el calibre de las limitaciones que Cebrián tuvo como director prácticamente desde el principio de su nombramiento. Utilizamos para ello cuatro tipo de fuentes: documentales de archivo, orales en forma de entrevista, hemerográficas mediante consulta de la colección de $A B C$, y bibliográficas.

Contamos, en primer lugar, con un hasta ahora inédito documento de posicionamiento ideológico-político que le fue entregado por la Junta de Fundadores y que aporta nuevas pruebas fehacientes no sólo de esas cortapisas sino también -y quizás de forma más sorprendente- de la desorientación que los principales "ideólogos" de $A B C$ tenían a la altura de 1975, año que finalmente resultaría tan crucial en la historia de España. Al hacerlo público por vez primera en su integridad deseamos realizar un servicio a la comunidad científica para que se puedan valorar con más precisión los episodios a los que nos referimos. Añade interesantes y clarificadoras constataciones de las dificultades a las que se tuvo que enfrentar en su tarea directiva. Otra fuente nueva utilizada son las respuestas que el propio Cebrián ofreció en una entrevista concedida a los autores, y que se complementan con algunas otras, no muy abundantes y que también recogemos aun siendo fuentes secundarias, realizadas por él a otros medios.

Además de estas fuentes contamos con la literatura principal publicada sobre el tema, de la que hemos ofrecido un resumen unos párrafos más arriba, y la consulta de la colección de $A B C$ durante los años de la dirección de Cebrián. Dados el objetivo principal perseguido y sus límites, hemos circunscrito la selección hemerográfica a unos pocos pero representativos episodios. No es nuestra intención, porque desbordaría las posibilidades de un artículo como este, analizar con detalle la línea ideológica del diario en aquellos años, suficientemente estudiada.

Desde esta situación de partida, el conocimiento de lo ya publicado y la aportación de nuevas fuentes documentales, es nuestro objetivo determinar las claves de la falta de autonomía de Cebrián para desarrollar un proyecto periodístico nuevo. Para ello se plantean dos hipótesis: que su papel real fue más el de un gestor de la redacción que el de un director de periódico, y que la responsabilidad del fracaso de $A B C$ no fue tanto suya como fruto del control ideológico que siguió teniendo Torcuato Luca de Tena en medio de notables luchas e intrigas internas en la empresa. 


\section{José Luis Cebrián, un director controlado desde dentro}

\subsection{A la búsqueda de un revulsivo}

Según los datos de la Oficina para la Justificación de la Difusión (OJD), $A B C$ se había situado entre los 200.000-210.000 ejemplares a finales de los años sesenta, pero de ahí pasó a descender gradualmente hasta situarse en 189.308 en el control de julio de 1973 a junio de 1974. También cayeron a partir de 1974 las páginas de publicidad, habitualmente una mina de oro para el diario, lo que se palió gracias a la elevación de las tarifas (Iglesias, 1980b: 447-473). En Madrid, la competencia del diario Ya estaba situando a este último casi a la par del periódico monárquico. Añádase además que, en el tablero político del tardofranquismo, el diario de La Editorial Católica aparecía además como más aperturista (García Escudero, 1984) que un $A B C$ que "estaba anclado [...] en el franquismo, y le faltaba capacidad de visión para otear un horizonte de libertad" (Olmos, 2002: 538). Aunque referidas a Torcuato Luca de Tena, se podían extender al diario dada su posición preeminente dentro de él como director y principal inspirador ideológico. Otro periódico de ámbito nacional, Informaciones, también se distinguía en aquellos postreros años de la dictadura por una línea liberalizadora que le llevó a su época de mayor esplendor (Crespo de Lara, 2008).

Desde el punto de vista periodístico, desde finales de los años sesenta, en $A B C$ ya existían larvados "síntomas de decadencia" (Alférez, 1986: 25). Estos se agravaron con dos fallidas aventuras empresariales: los talleres gráficos de Barajas y el transoceánico proyecto del $A B C$ de las Américas, lanzado en Nueva York en 1972. Junto a las graves consecuencias financieras para la casa, en unos tiempos que se verían afectados por la crisis petrolera de 1973, perdieron también $A B C$ y Prensa Española parte de su señera reputación. Colateralmente, y ya en un ámbito más personal, acabó especialmente dañado dentro de la casa Torcuato Luca de Tena, que fue el principal impulsor de la aventura norteamericana sin dejar de ser oficialmente director del $A B C$ español.

En estas circunstancias, el fallecimiento de Juan Ignacio Luca de Tena en enero de 1975 desencadenó una crisis de notables dimensiones. Si ya habían existido anteriormente otros intentos, finalmente frustrados, de defenestrar a Torcuato como director, la unión de todos estos elementos hizo que -en esta ocasión- quienes propugnaban su remoción salieran triunfantes. El problema estribaba en la sucesión, que se reducía a dos o tres nombres: su hermano menor Guillermo, el subdirector Luis María Anson y algunos apuntan también que el director adjunto Pedro de Lorenzo. Los dos últimos, en distintos puestos, tenían el inconveniente de ser considerados hombres de Torcuato, ahora caído en desgracia. La solución final, ecléctica y un tanto 
sorprendente, fue José Luis Cebrián, con quien los Luca de Tena ya habían mantenido contactos desde 1969, como se ha explicado. Comentando esta decisión que apartó a hombres de la casa, Cebrián ha declarado de forma un tanto escueta y enigmática, o quizás solo discreta: "Eso hizo la empresa, algo pasaría" (Periodista Digital, 2014).

Desde un principio su contratación fue explicada a ojos de la opinión pública como una apuesta meramente profesional, basada en la solvencia y prestigio ganados por Cebrián en su andadura periodística anterior y no en su pertenencia al Opus Dei como algunas informaciones rumoreaban. Para desmentirlos, $A B C$ publicó un editorial que acompañaba, el 27 de febrero, la noticia de su nombramiento. Se titulaba: "Los delirantes informes en torno a $A B C^{\prime \prime}$ (27-2-1975: 29), y en él se hablaba, entre otras cosas, de "las dotes excepcionales de profesional del periodismo" que tenía Cebrián, y "su honesta, independiente y veraz profesionalidad".

Según cuenta Pérez Mateos (2002: 504), en dicho editorial intervinieron cinco personas, y contó con el toque final de un histórico de la casa como Luis Calvo. Se quiso cortar así, de forma tajante, con la reacción interna de protesta que protagonizaron hombres fuertes de la redacción que firmaron una carta contraria a ese nombramiento, entre ellos: Miguel Torres, José Javaloyes, José Luis Martín Descalzo, Pedro Crespo y Diego Jalón, más partidarios de que fuese Guillermo Luca de Tena quien asumiera la dirección. Pero la decisión de Torcuato, presidente de la Junta de Fundadores, estaba ya tomada. En todo caso, el recibimiento a Cebrián por parte de la redacción fue entre reticente y hostil. En la reorganización de funciones, Luis María Anson pasó a ser director del semanario Blanco y Negro, y a Pedro de Lorenzo se le situó al frente de la Editorial Prensa Española. "Me voy a meter en un volcán", pensó Cebrián; pero aun así aceptó y se dijo para sí mismo: "si lo paso mal, pues lo paso mal" (Periodista Digital, 2014). Llegar a ser director de $A B C$ era una oferta difícilmente rechazable pese a las circunstancias.

Se confiaba en su currículum anterior para revitalizar el periódico, al estilo de lo que ya había hecho en otros medios, pero al mismo tiempo se le pusieron varias cortapisas de entrada. Una primera fue la imposibilidad de formar un equipo de confianza en torno suyo. Así lo recuerda el propio Cebrián: "Cuando me fichan en $A B C$ digo que yo querría montar un pequeño equipo y me dicen: 'es que hay mucha gente, quizá más adelante, si hay algo es que nos sobra gente'. Con lo cual yo tuve ahí una cierta sensación de orfandad, pues no llevé ni mi segundo de a bordo ni un equipo" (Cebrián, 2006).

Según las cifras que proporciona Iglesias, Prensa Española contaba en 1975 con 1.965 trabajadores en plantilla en Madrid, y 451 en Sevilla. Solo 184 eran de Redacción (Iglesias, 1980b: 479-481). Así pues, tuvo que contar con todo el equipo anterior y sólo pudo hacer algún fichaje de sustitución, como fue el caso de Pedro J. Ramírez, a quien ya había tenido a sus órdenes en La Actualidad Española. Un accidente mortal de tráfico de un redactor de deportes, Joaquín Iglesias, le dio la oportunidad de rescatarlo 
para $A B C$, primero con un contrato temporal (Ramírez y Robles, 1991: 121; Cebrián, 2006). Pronto pasaría a la sección de Política. También contrataría después a Pilar Urbano, pero ninguno de los dos ocupó puestos de responsabilidad. Los dos nuevos subdirectores de Cebrián serían hombres de la casa como Miguel Torres y Santiago Arbós.

\subsection{La Junta de Fundadores y el Consejo de Dirección}

Además de las limitaciones para formar su propio equipo, Cebrián se vio sometido a lo que Alférez llamó, quizás con ciertas dosis de exageración, "una maquinaria para tenerle atado de pies y manos" (Alférez, 1986: 37). Se refería con ello a dos instrumentos de control y orientación ideológica ya existentes: la Junta de Fundadores, establecida a raíz de la Ley Fraga, y el Consejo de Dirección. A comienzos de 1975 componían la Junta: Torcuato Luca de Tena como presidente, Benito Pico Martínez yerno del fundador- como vicepresidente, más Guillermo Luca de Tena, su tío Fernando, y Andrés Fagalde Luca de Tena (Iglesias, 1980b: 422). Por su parte, el Consejo de Dirección nombrado con los cambios de febrero estaba formado por Torcuato Luca de Tena como presidente, Pedro de Lorenzo como vicepresidente, y cinco vocales, a saber: Guillermo Luca de Tena, Nemesio Fernández-Cuesta, Luis Calvo, el propio José Luis Cebrián, y José María Ruiz Gallardón, que actuaba como secretario (Olmos, 2002: 536).

Olmos resume la situación diciendo que uno de los principales problemas de Cebrián fue que Torcuato Luca de Tena se había "cuidado personalmente de que aquél sea prácticamente apartado de configurar la línea política del diario" (Olmos, 2002: 535), terreno que se siguió reservando para él y sus afines. En otras palabras, lo que se le permitió a Cebrián fue modernizar el diario en aspectos como el diseño, las secciones, las portadas, el adelanto en la hora del cierre y la creación de series -a las que era tan dado desde los tiempos de El Alcázar- que introdujeran un mayor dinamismo en el producto y atrajeran al lector (Alférez, 1986: 38). Pero el consejo de dirección, que "constituía la verdadera dirección del periódico, más que el propio director, no alcanzó a presentir el posible cambio [político]" (Edo, 1994: 63). Y fueron los posicionamientos políticos e ideológicos del diario y de sus primeras firmas los que fueron alejando a $A B C$ de seguir la pulsión de cambio que se palpaba en la sociedad española.

Cabe preguntarse si fue Cebrián consciente de ello desde el principio. Según su testimonio, si bien dicho de una forma suave, sí. Sabía primero que "el $A B C$ ha sido siempre un periódico de línea conservadora". Además, los editoriales se publicaron con su consentimiento: "Yo firmé, vamos. Porque el responsable ante la ley era el director, o sea, yo". Y continuaba diciendo: "Si en esa empresa hay una estructura en 
la que hay un consejo de dirección, y antes por encima una junta de fundadores, eso se resolvía dentro" (Cebrián, 2006). Ha declarado además que la Junta de Fundadores era "existente y muy activa" (Periodista Digital, 2014). Según cuenta Miguel Torres, "eran Torcuato y sus más próximos consejeros los que decidían la mayor parte de los editoriales" (Olmos, 2002: 535). Sobre Ruiz Gallardón, Cebrián ha recordado, alabando su categoría intelectual, que "dictaba el editorial a una secretaria y no había que corregir ni una letra" (Periodista Digital, 2014).

En este contexto hay que encuadrar la entrega de un documento de cuatro páginas, escuetamente titulado "Normas", por parte del Consejo de Dirección de $A B C$ al nuevo director José Luis Cebrián, que anotó a mano y subrayado "1975" en la zona superior derecha. En un total de dieciséis puntos escritos a doble espacio se condensaban los planteamientos ideológico-políticos a los que el diario debía atenerse. Dado su evidente interés lo reproducimos en su integridad y tal como se escribió en el original para luego pasar a comentarlo.

\section{Las "normas" del $A B C$ de 1975}

1a.- El 18 de Julio de 1.936 es una frontera histórica. ABC participó activamente en la creación del espíritu que hizo posible el 18 de Julio y debe seguir siendo consecuente con aquél [sic] punto de partida.

2a.- Algunos de los Gobiernos nacidos, y la política emanada con posterioridad a aquella frontera histórica, comprometieron grandemente al Gobierno español con una política nazista, fascista o pseudonazista o pseudofascista con la que el periódico ni comulgó ni debe de comulgar jamás por lo que tenía de "expropiación fascista del Movimiento".

3a.- Ello no obsta para mantener un gran respeto a la Falange, a la persona de su fundador y a sus seguidores actuales como integrantes de la España surgida del 18 de Julio. Con un continuado matiz de protesta por la usurpación de la totalidad del Movimiento, pero con un reconocimiento de la realidad de su presencia activa antes, en y después del 1ㅇ de Abril de 1.939.

4a.- Este es uno de los puntos delicados de toda nuestra matización política. No estamos con Falange respecto a su concepción fascista o totalitaria del Estado. No estamos con Falange respecto a la usurpación general de los "ideales que comulgaron en los principios generales del 18 de Julio" abarcando en un todo a lo que sólo era una parte. Pero sí creemos que se debe defender una posición 
cualificada de Falange en la presencia política española como representante de un sector activo y real.

5a.- ABC lamenta que en los problemas de la sucesión no haya sido respetado el orden dinástico. Pero ni puede ni debe mantenerse en situaciones empíricas e imposibles como las que mantuvieron alejada de la política española durante los últimos siglos a la muy noble facción carlista.

6a.- Como complemento de lo anterior, insistimos en que una real y verdadera aportación al pensamiento político español se debe a los tradicionalistas que quedaron fuera de juego por la adscripción a unas posibilidades dinásticas imposibles. $A B C$ debe de estar con los pies asentados muy en el suelo de la realidad y no jugar a lo que es imposible pero sí jugar dentro de una consecuencia con los demás puntos que más adelante se expresan.

7ạ.- Hay que partir del hoy y del aquí. Puede y debe promoverse una evolución partiendo de la realidad presente. Nada de revoluciones. Mas sí apoyar aquellas evoluciones que sean necesarias.

8a.- La primera y más grande evolución para dar al régimen español surgido del 18 de Julio -que defendemos- se debe a Alberto Ullastres; la segunda a Fraga Iribarne; la tercera a Arias Navarro.

9ạ.- Hay que apoyar esta línea histórica de evolución.

10a.- Hay que tener muy presente el ejemplo de Portugal. Las diferencias entre uno y otro país son ingentes y no es aquí ocasión de desarrollarlas. No obstante, ambas pueden parecerse al hecho histórico de salidas de una Dictadura.

11a.- Repudiamos toda política semejante a la seguida por el profesor Calvo Serer respecto a sus contactos con el comunismo español en el exilio.

12a.- Apoyamos el espíritu de la política (pero no la letra) de Carlos Arias Navarro en el sentido de iniciar un necesario aperturismo que permita crear un conglomerado de organizaciones de fuerzas políticas no marxistas que, con una $u$ otra tendencia no dejen desguarnecidos de organización a los movimientos políticos de derecha, centro, centro-izquierda o izquierda no marxista.

13a.- La adscripción de esta política aperturista no significa concordancia con ninguna de ellas en particular. La posición del periódico puede ser partidaria de ese aperturismo, permitiendo el juego político de fuerzas con las que no comulgamos sin necesidad de comprometer nuestro pensamiento o nuestra actitud con ninguna de ellas. 
14a.- El periódico debe mantener independiente de todas ellas, en el sentido de no participar ni de que participen sus dirigentes visibles, en ninguna organización política concreta y determinada. Es decir, que la primera norma del periódico respecto a los hombres políticos del país debe ser su absoluta y radical independencia.

15a.- Lo anterior no obsta para dar calor e incluso impulso, desde fuera -jamás desde dentro- a cualquier organización política noble, coincidan o no coincidan sus programas con nuestro criterio.

16a.- Dentro de lo anteriormente dicho, hay muchos y fundamentales puntos de fricción con la política seguida por los últimos Gobiernos. En no pocas ocasiones por coincidir con el espíritu de la línea de sus principios, y no con la realización efectiva de los mismos por considerar que han traicionado o desvirtuado aquéllas [sic]. Pero esto pertenece ya a la política de cada día, ajena a la defensa de las líneas generales que han de inspirar $A B C$. (Normas, 1975)

\section{Análisis y consecuencias}

\subsection{Un aperturismo entre pragmático y confuso}

Tienen estas "Normas" una naturaleza de documento programático, en el sentido de que fijan las posiciones que ha de seguir el diario -y que de hecho estaba siguiendo, cabría añadir- ante los acontecimientos de la España de 1975. Se sitúan más bien en el ámbito político que en el ideológico de los principios editoriales tradicionales del $A B C$ desde su fundación, que se dan de alguna manera por supuestos. Por ello poseen un cierto carácter pragmático, bajando incluso al terreno de casos específicos. Suponen, por tanto, la aplicación de los principios clásicos del diario a la realidad del último tardofranquismo. Son entregados a Cebrián en unos momentos en los que, por ejemplo, se habían producido recientemente hechos relevantes como el espíritu del 12 de febrero, la revolución de los claveles en Portugal, la primera enfermedad de Franco y la constitución de la Junta Democrática en París. Todos ellos sobrevuelan, explícita o implícitamente, las páginas del documento.

Las dieciséis normas pueden agruparse en seis puntos temáticos principales: el 18 de julio como punto de partida indiscutido; el reconocimiento y los recelos hacia Falange; el pragmatismo en la cuestión monárquica o sucesoria; la apuesta por el aperturismo político y, como consecuencia, el apoyo crítico al espíritu del 12 de febrero; un 
antimarxismo sin concesiones; y la proclamación de una independencia no neutral de organizaciones políticas concretas. Pasemos a analizarlas con algún detalle.

A la altura de 1975, $A B C$ se reconoce aún partícipe del espíritu que alentó la creación del régimen de Franco salido de la guerra civil. Así se señala con claridad en la primera de las normas. No obstante, se muestra crítico con la "usurpación" o "expropiación fascista" que Falange hizo del Movimiento, lo cual no quita que se reconozca su papel "activo y real" y "una posición cualificada" dentro del régimen. En el fondo de esta exposición laten las conocidas rivalidades políticas internas entre falangistas y monárquicos, presentes desde los inicios de la dictadura.

La cuestión monárquica se aborda en las normas quinta y sexta. No hacen sino corroborar la conducta que $A B C$ adoptó en 1969 cuando Franco nombró sucesor suyo a título de Rey al príncipe Juan Carlos de Borbón, plasmada en un editorial titulado "Con la sangre de nuestros reyes" (Olmos, 2002: 443-456). Junto al lamento por no haberse "respetado el orden dinástico" (por parte de Franco evidentemente, aunque no se cite expresamente), se reivindica la aportación doctrinal de los tradicionalistas al pensamiento político español pero se les critica su "adscripción a unas posibilidades dinásticas imposibles". Como contrapunto, y para evitar ese ostracismo, $A B C$ se declara pragmático y realista, y prefiere jugar, por tanto, a lo posible partiendo "del hoy y del aquí".

Es entonces cuando declara, entre las normas séptima a novena, sus preferencias especificas en cuanto a la necesaria apertura del régimen. La dinámica política del tardofranquismo estaba dominada internamente por las tensiones entre aperturistas de diversos signos y continuistas. $A B C$ se sitúa entre los primeros apoyando lo que llama "evoluciones". Así, en plural, porque apoya expresamente tres líneas de evolución que tienen tres nombres propios: Ullastres, Fraga y Arias Navarro. Nótense, a este respecto, dos cosas: primero, que las normas vuelven a hacer una proclamación de defensa del régimen surgido el 18 de julio; y segundo, que denomina "línea histórica de evolución" al conjunto de estas tres evoluciones. Se trata, por consiguiente, de un aperturismo que no pretende ir más allá de las fronteras políticas del franquismo y que intenta aglutinar fuerzas políticas bastante heterogéneas e incluso incompatibles entre sí en aquellos momentos. Los tecnócratas, a quienes Ullastres podría representar, habían tenido serios encontronazos con el sector de Fraga, y habían sido apartados del gobierno por Arias. Y este último no mantenía fluidas relaciones con Fraga, como se demostró en la negativa de este a participar en el asociacionismo político promovido por aquel.

Podría argüirse que, con esta declaración, los hombres de $A B C$ pretendían señalar su apoyo a diferentes estrategias aperturistas habidas en la España de los años sesenta y primeros setenta, por más que fueran poco compatibles entre sí desde el punto de vista de las pugnas personales o de grupo. No obstante, se instala cierta confusión 
cuando en la escueta norma novena se dice: "Hay que apoyar esta línea histórica de evolución", como si fuera una sola, clara y distinta. Sí se registra un apoyo más razonado al espíritu -palabra con que la prensa de la época lo bautizó- de la nueva política del presidente Carlos Arias; al espíritu, se dice, "pero no a la letra", seguramente debido a la falta de concreción y a las dudas que lo caracterizó.

La cuestión del marxismo aparece expresa o tácitamente mencionada en las normas décima a duodécima. Cuando se habla del ejemplo de Portugal no se puede olvidar la deriva comunista en que la revolución de los claveles podía caer. Y $A B C$ era consciente de que la vecina España tendría que salir, más temprano que tarde, de su propia dictadura. En este sentido, en uno de los puntos quizás más contundentes de las normas por el verbo utilizado -"repudiamos"- se rechazaba cualquier política de acercamiento a los comunistas como el que había protagonizado el monárquico juanista Rafael Calvo Serer en julio de 1974, cuando presentó con Santiago Carrillo en París la Junta Democrática de España como plataforma de partidos y personalidades de oposición al franquismo.

Las últimas normas se explayan en torno a la postura del periódico, en el seno de "un necesario aperturismo", en relación con los movimientos que tendrían cabida dentro de "un conglomerado de organizaciones de fuerzas políticas no marxistas". La consigna principal es la "absoluta y radical independencia", sin permitir que los "dirigentes visibles" del periódico participen en ninguna de ellas. Esto no estaba reñido, sin embargo, con "dar calor e incluso impulso, desde fuera -jamás desde dentro- a cualquier organización política noble". Expresado esto en la penúltima de las normas, la última vuelve a emitir juicios acerca de la falta de "realización efectiva" de medidas aperturistas por parte de los últimos gobiernos. Pero es entonces cuando, seguramente conscientes de que se metían en terrenos pantanosos y contingentes, terminaban diciendo que "esto pertenece ya a la política de cada día" que, sorprendentemente, declaraban "ajena a la defensa de las líneas generales que han de inspirar $A B C^{\prime \prime}$.

\subsection{Una incompleta modernización del periódico}

"En los dos años y medio que dirigí el $A B C$ no dominé la dirección", ha confesado José Luis Cebrián en 2006. Llevar por completo las riendas de un periódico suele exigir un equilibrio o entendimiento entre la parte editorial y de opinión y la propiamente profesional que involucra al resto de las secciones. Si además se trata de un diario histórico y de referencia nacional, ese tirar juntos del carro en la misma dirección en los dos ámbitos se hacía más imprescindible para levantarlo. A Cebrián le dejaron pronto muy claro que su terreno de actuación era el profesional-periodístico pero que la orientación ideológica y el posicionamiento político pertenecían prácticamente a los 
mismos que lo habían llevado hasta entonces. Las "Normas" que se le entregaron marcaban los límites, que él -todo hay que decirlo- aceptó y asumió. Aludiendo a las palabras ya mencionadas de Pedro J. Ramírez, entonces joven redactor de $A B C$, que describían a Cebrián como un "rehén" de la situación interna, éste ha aclarado: "Bueno, yo lo que tenía era un presidente de la junta de fundadores que era Torcuato. A mí no me repugnaban las líneas que se decían dentro del periódico" (Cebrián, 2006). No repugnar no es, sin embargo, sinónimo de compartir.

Conjugar una modernización y popularización del $A B C$, como se le encargó a Cebrián debido a su reconocida trayectoria profesional, con el mantenimiento de la línea básicamente conservadora que le venía caracterizando en los últimos años del franquismo, era quedarse en un medio camino que al final no satisfacía ni a unos ni a otros. Alférez ha descrito esos años como "complejos, zigzagueantes, en que $A B C$ daba una de cal (fidelidad a su línea liberal independiente) y otra de arena (colaboración cómplice con algunas arbitrariedades o pasos atrás del franquismo)" (Alférez, 1986: 26). El diario monárquico se vio en definitiva desbordado por el ritmo más acelerado de la transición a la democracia, como algunos autores han puesto de manifiesto tras analizar sus posiciones y actitudes en los inicios: "principal defensor del continuismo franquista de Arias, y tras su relevo, mantiene un apoyo crítico a Suárez, mientras su editor se alinea con el proyecto neo-franquista de Fraga" (Guillamet et al., 2015: 231)

Cebrián ha afirmado que él "tenía ambiciones democráticas (...) pero desde el punto de vista del periódico la línea editorial escrita estaba más en línea de continuidad del franquismo que del rupturismo". Y añade que "el que presidía la Junta de Fundadores era Torcuato Luca de Tena y no Guillermo. Eso produjo desazón en la redacción y en la dirección" (Cebrián, 2006). En ese enfrentamiento no quiso mediar sino "observar las cosas y tener prudencia" (Periodista Digital, 2014).

Aquellas "Normas" de 1975, si se examina la colección del periódico hasta 1977, siguieron estando presentes -mutatis mutandis- como líneas de interpretación fundamentales del acontecer español. Cambiaron las circunstancias políticas tras la muerte de Franco pero los encargados de plasmar la posición de $A B C$ continuaron siendo los mismos. Entretanto, otros periódicos, tanto tradicionales como $\mathrm{Ya}$ e Informaciones o nuevos como El País y Diario 16, adquirieron mayor credibilidad democrática -y en algunos casos también más ventas- que el de Prensa Española.

Algunos de los intentos de Cebrián, desde la parte informativa, por dotar de mayor dinamismo a $A B C$ y conectarlo con la actualidad, resultaron insuficientes. La serie "Cien españoles para la democracia", "Parlamento $A B C$ " y las "Tertulias Electorales" tuvieron eco en la opinión pública, pero no se vieron acompañadas por cambios significativos en las páginas de opinión, donde -fuese como editorialistas o como columnistas habituales- Torcuato Luca de Tena, José María Ruiz Gallardón y Gonzalo Fernández de la Mora marcaban una pauta de recelo y temor ante los reformas. Destacado fue el 
caso del duro editorial que se publicó un día después de que Felipe González apareciera en doble plana de hueco como uno de los cien españoles de la sección antedicha, y que empezaba diciendo como excusa para refutar algunas de sus declaraciones: "A los lectores de $A B C$ no puede extrañarles que (...) nos sintamos obligados a puntualizar con el máximo respeto algunos extremos..." (Olmos, 2002: 540541).

Ciertamente había sectores dentro del propio Consejo de Dirección -y a un nivel inferior también en la redacción- que no comulgaban con esa forma de ver las cosas, pero no pudieron imponerla al mostrarse "más pusilánimes o acomodaticios" (Olmos, 2002: 536). Un estallido notorio de las discordias internas llegó con las elecciones generales del 15 de junio de 1977: Torcuato Luca de Tena se presentó en las listas del Senado por Alianza Popular, y su cuñado Nemesio Fernández-Cuesta por UCD. El punto 14 de las "Normas" de 1975, que prohibía la participación activa de los dirigentes de $A B C$ en las fuerzas políticas, quedaba incumplido. Bien es cierto que la Junta de Fundadores hizo pública una extensa nota en la que daba libertad a todo su personal, directivos incluidos, para desarrollar las actividades políticas que estuvieran de acuerdo con sus creencias (Iglesias, 1980b: 427). Además, tanto Torcuato como Fernández-Cuesta renunciaron durante la campaña a sus cargos como presidente de la Junta de Fundadores y consejero delegado de Prensa Española respectivamente, pero la percepción externa de sus vinculaciones políticas fueron inevitablemente perjudiciales para el diario. De alguna manera, se aireaban públicamente las discrepancias internas existentes.

En medio de estos enfrentamientos fraternos en las alturas del sector más continuista de Torcuato y el más aperturista de Guillermo, la figura de Cebrián no pudo ser más que la del mero espectador. "A mí -ha dicho- me tocó estar en la vía (...) en la que venían dos trenes enfrentados, dos máquinas, dos locomotoras, y que me cogieron en medio" (Cebrián, 2006).

\section{Discusión y conclusiones}

La designación de José Luis Cebrián como director de $A B C$ a comienzos de 1975 causó revuelos internos en el periódico y en la empresa editora porque algunos intuían que se podía desvirtuar el espíritu de la casa al dejar el periódico en manos de un buen profesional pero advenedizo. Se temían las consecuencias, pero los dirigentes de $A B C$ optaron por una solución no común en su historia dado que los síntomas de crisis eran ya evidentes y progresivos. No obstante, si algunos pensaban que Torcuato Luca de Tena había sido el principal damnificado de aquellas pugnas tras la muerte de su padre Juan Ignacio, la forma en que recabó para sí y su círculo más cercano el control 
ideológico y político del diario lo desmintió. El principal damnificado, entonces, pasó a ser el nuevo director, a quien se le dejó una capacidad de maniobra reducida a los aspectos fundamentalmente periodísticos: gobierno de la redacción, renovación del diseño del diario, iniciativas de tipo informativo, etc. Es decir, aquellos más puramente técnicos, profesionales y de gestión diaria.

No parece, pues, del todo exacta esta afirmación de Olmos al hablar de la evolución de $A B C$ durante la dirección de Cebrián: "El caso es que el virus de la defensa a ultranza del franquismo que había padecido el $A B C$ en los últimos tiempos, y que el nombramiento de Cebrián había pretendido erradicar, continuaba activo" (Olmos, 2002: 537). Parte de la premisa de una supuesta capacidad de renovación de la que Cebrián careció porque le fue negada precisamente por quien le nombró, es decir, Torcuato Luca de Tena, cuya defenestración o caída en desgracia en 1975 resultó más formal que real. Sólo cuando su hermano Guillermo cesó a Cebrián y se erigió también en director del diario, perdió Torcuato su poder.

Algunos libros sobre $A B C$ han empleado metáforas de claras connotaciones regias para calificar el período de dos años y medio de dirección de José Luis Cebrián -“La Regencia" (De Lorenzo, 1983), "El interregno" (Alférez, 1986)-, lógicas al tratar de un diario monárquico por excelencia. Aunque algunos autores, especialmente Alférez, valoran las novedades e iniciativas que Cebrián llevó a cabo, no dejan de presentar esa etapa como un paréntesis entre las direcciones de dos pesos pesados de la casa como los hermanos Torcuato y Guillermo Luca de Tena, a la vez enfrentados entre sí. Ha prevalecido, desde el punto de vista histórico, este marco general más amplio produciéndose cierta minusvaloración de los esfuerzos realizados por Cebrián. Si estos resultaron -en términos generales- baldíos, se debieron en buena medida tanto al duelo en las alturas que se registraba en la casa como al control ideológico-político establecido por Torcuato y que encastilló a $A B C$ en unas posiciones que le hicieron perder puntos y credibilidad en momentos decisivos de la transición.

Las "Normas" que recibió nada más tomar posesión del cargo dibujaban un aperturismo bastante confuso y dejaban la interpretación del día a día en manos de Torcuato. Dicha interpretación fue más bien conservadora, tendente hacia las políticas de Alianza Popular y refractarias hacia las reformas más importantes promovidas por el gobierno Suárez y exigidas por otros partidos de la oposición democrática, tales como la legalización del Partido Comunista y la amnistía general, entre otras muchas.

Atribuir, pues, a Cebrián el fracaso de $A B C$ en la entrada en la transición resulta demasiado simple e incluso injusto. De hecho, las cifras de difusión del diario continuarían bajando, incluso a mayor velocidad, entre 1978 y 1982, hasta llegar a los 127.000 ejemplares. El mayor pulso informativo de que le intentó dotar le venía de su experiencia en El Alcázar en los años sesenta, donde instauró con éxito lo que llamó el "periodismo en tres dimensiones: dinámico, documentado y divertido" (Periodista 
Digital, 2014). Varias de sus principales iniciativas para enderezar el rumbo del diario iban encaminadas en esa dirección. Pero resultaba complicado dotar de esas características a un diario ya muy hecho y con mucha historia como $A B C$, que no era además un vespertino como El Alcázar y cuyo público era diferente.

Cebrián, que se tuvo siempre a sí mismo como un periodista más bien apolítico, se vio enfrentado a una tarea que, por los motivos explicados, le superó y que además tuvo muchas dosis de política y de luchas internas en la propiedad en las que no quiso participar. Ha admitido que "dirigió con dignidad pero sin acierto" (Alférez, 1986: 36), si bien no le ayudaron ciertamente ni las circunstancias que le tocó vivir ni las personas de las que se vio rodeado. Las dificultades a las que tuvo que hacer frente, también las de carácter empresarial y periodístico, tuvieron un trasfondo inevitablemente político, del que las "Normas" que le fueron entregadas resultan un esclarecedor exponente. Su nivel de autonomía para desarrollar un proyecto periodístico propio se reveló más bien escaso y, pese a haber desarrollado distintas iniciativas -algunas con impacto en la opinión publica-, su papel quedó relegado a la gestión profesional más que a una auténtica dirección del diario y de su rumbo.

\section{Referencias bibliográficas}

AGUILAR, M.A. (1982): El vértigo de la prensa, Madrid, Mezquita.

ALFÉREZ, A. (1986): Cuarto poder en España. La prensa desde la Ley Fraga 1966, Barcelona, Plaza \& Janés.

BARRERA, C. (1995): Sin mordaza. Veinte años de prensa en democracia, Madrid, Temas de Hoy.

BUSTAMANTE, E. (2013): Historia de la Radio y la Televisión en España. Una asignatura pendiente de la democracia, Barcelona, Gedisa.

Entrevista de los autores a José Luis Cebrián (21/12/2006).

CRESPO DE LARA, P. (1988): La prensa en el banquillo, 1966-1977, Madrid, AEDE. - (2008): Informaciones: la década del cambio, 1968-1978, Santander, Tantín.

DE LORENZO, P. (1983): Diario de la mañana, Badajoz, Universitas.

EDO, C. (1994): La crisis de la prensa diaria: la línea editorial y la trayectoria de los periódicos de Madrid, Barcelona, Ariel. 
FORCADA, D. y LARDIÉS, A. (2010): Anson. Una vida al descubierto, Madrid, La Esfera de los Libros.

GARCÍA-ESCUDERO, J.M. (1984): Ya: medio siglo de historia, 1935-1985, Madrid, BAC.

GUILLAMET, J.; SALGADO, F. y ITURRATE, M. (2015): “El apoyo de la prensa a la transición española. Actitudes de los periódicos ante el Rey, el Gobierno y los partidos (1975-1977)", en PINEDA SOTO, A. (ed.) Recorridos de la prensa moderna a la prensa actual. México: Universidad Michoacana de San Nicolás de HIdalgo y Universidad Autónoma de Querétaro, pp. 211-236.

IGLESIAS, F. (1980): "La crisis de la prensa diaria en España” en Nuestro Tiempo, no 308,1980 , pp. 4-21.

- (1980b): Historia de una empresa periodística. Prensa Española. Editora de ABC y Blanco y Negro (1891-1978), Madrid, Prensa Española.

"Los delirantes informes en torno a $A B C$ ", $A B C$, 27-2-1975, 29.

NOGUÉ, A. y BARRERA C. (2006): La Vanguardia. Del franquismo a la democracia, Madrid, Fragua.

“Normas” (1975). Copia del documento entregada por José Luis Cebrián a los autores.

OLMOS, V. (2002): Historia del ABC, Barcelona, Plaza \& Janés.

PÉREZ LÓPEZ, P. (1994). Católicos, política e información. Diario Regional de Valladolid, 1931-1980, Valladolid, Universidad de Valladolid.

PÉREZ MATEOS, J.A. (2002). ABC. Cien años de "un vicio nacional". Historia íntima del diario, Madrid, Libro-Hobby.

Periodista Digital (2014): Entrevista a José Luis Cebrián. Disponible en Internet (3/4/2014): https://www.youtube.com/watch?v=TgqVpX1OwqQ

RAMíREZ, P.J. y ROBLES, M. (1991): Pedro J. Ramírez. El Mundo en mis manos, Barcelona, Grijalbo.

RODRÍGUEZ VIRGILI, J. (2005): El Alcázar y Nuevo Diario. Del asedio al expolio (19361970), Madrid, CIE-Dossat.

SANTOS, F. (1995): Periodistas. Polanquistas, sindicato del crimen, tertulianos y demás tribus, Madrid, Temas de Hoy.

ZUGASTI, R. (2007): La forja de una complicidad. Monarquía y prensa en la Transición española (1975-1978), Madrid, Fragua. 